\title{
On The Construction of Teaching Team in Chinese Application-Oriented Universities
}

\author{
Shijie Wang \\ Correspondence: Shijie Wang, Institute of Higher Education, Hefei Information Technology University, Hefei, China.
}

Received: December 19, 2021

doi:10.11114/jets.v10i2.5454

\author{
Accepted: January 17, 2022 \\ Online Published: January 19, 2022 \\ URL: https://doi.org/10.11114/jets.v10i2.5454
}

\begin{abstract}
Teachers are the base of education plans. Teachers of application-oriented universities are engaged in educational teaching and academic research, and they are the main body of human resource management in colleges and universities. The "construction of the teaching team" in application-oriented universities is to, based on school positionings, build a rationally structured and high-quality teaching team and an improved training and evaluation incentive mechanism, continuously improve teachers' professionality and morality and strengthen the stability of teaching staff.
\end{abstract}

Keywords: application-oriented universities, double-qualified-type teachers, teacher education, part-time teachers, school-enterprise cooperation, evaluation incentives

\section{Introduction}

As the central part of the higher education system, application-oriented universities are defined as "professional applied universities and colleges whose position is between research universities and skill-based vocational colleges. They are also institutions for training professionals, cadres and managers at all levels such as engineers, economists, lawyers, teachers and clinicians" (Pan, 2006, p.1). Mainly concentrated in prefecture-level cities, application-oriented universities account for over $60 \%$ of the newly-built undergraduate colleges. These institutions are often co-managed by the provincial and municipal governments, and most of the students come from the local areas. Such a special development process and student structure determine that the main task of application-oriented universities is to cultivate applied talents that meet the local needs. In other words, its development direction and goal of talent cultivation is highly in line with the social demand. Since 2000, application-oriented universities have gradually formed their own characteristics and school-running concepts, and have also been initially recognized by society. Over the past two decades, the development of applicationoriented universities can be roughly divided into three stages, namely, the stage of merging and upgrading (2000 2004), the stage of forming core characteristics and rapid development (2005 2008), and the stage of seizing opportunities and transforming (2009 to the present).

Corresponding to the above three stages, the construction of the teaching staff in application-oriented universities has also gone through three stages: integration, rapid growth and continuous optimization. In the stage of adaptation and integration, teachers adapted to the new school environment, culture, goals and requirements, and interpersonal relationships. The rapid growth stage saw professors with senior titles and a large number of fresh graduates with postgraduate degrees being recruited. Finally, when the application-oriented university is in the transformation period, the construction of the teaching staff shifted its focus from the sole pursuit of a number to connotation and quality. In this stage, the structure of teachers' degrees, title, and age and the proportion of full-time teachers and "double-qualified" teachers are continuously optimized. This is understandable as the application-oriented university, which is in the stage of transformation and development, has put forward unique requirements for talent training and higher ability demands for teachers (Liu, 2017). Different from undergraduate academic colleges and vocational colleges, the aim of applicationoriented universities is to develop high-quality application-oriented talents and senior professionals, who should equip themselves with rich theoretical knowledge and strong practical ability (Song et al., 2015).

As teachers from application-oriented universities, therefore, they should first clarify the orientation of talent training, keep pace with the times, and update their educational beliefs. Based on school goals, they need to change their concepts of talents, correctly understand the characteristics of students in knowledge, ability, quality, and then improve their own personal knowledge and ability structures accordingly. Secondly, they should grasp the frontier trends of science and technology and improve their research ability. Specifically, teachers can start from practical problems and needs, take the 
market demand as their guide, and serve the local economy. This requires more research being conducted on the transformation of scientific and technological achievements into productivity. In addition, as teaching and research are closely linked, the improvement of teachers' research level may also contribute to promoting their teaching quality. Thirdly, it is necessary for teachers to strengthen the connection between practical teaching and social service and improve their ability of professional application. After all, the fundamental difference between teachers of application-oriented universities and research universities lies in their application ability. In application-oriented universities, practical professional ability and teaching ability are essential for teachers. Generally, teachers' ability structure is mainly reflected in three aspects: practice-oriented teaching ability, practical professional ability that can guide operation, and social service ability focusing on application (Liu, 2017; Xu, 2013). With practical ability at the core, the three aspects complement and promote each other.

\section{The Current Situation of the Teaching Team in Application-Oriented Universities}

The construction of the teaching team is crucial to the development of application-oriented universities (Dong, 2009). A team of teachers with exquisite ability, reasonable structure and full of vitality plays a key role in building a high-level and distinctive application-oriented university (Liu, 2017). In turn, a correct position of applied universities helps to clarify the basic idea and developmental direction of building the teaching team. On the positioning issue, Pan (2008) believes that no matter from the national- or provincial-level layout of higher education or from the developmental prospect, most application-oriented universities should be positioned as follows: (1) based on cities and serving local areas; (2) becoming vocational-technical undergraduate universities (5B) or professional applied undergraduate (5A-2) universities; (3) becoming teaching universities or teaching-oriented research universities (Pan, 2008). It is clear that, according to these positions, teachers play a fundamental and core role in application-oriented universities.

Currently, the development of the teaching team in application-oriented universities has made many achievements, though great difficulties still exist. Teachers' development is restricted both by subjective and objective factors. As for the structure of teaching staff, the number of teachers is insufficient, and the student-teacher ratio remains high; the age structure is biased with more older teachers; most teachers are masters, and it is difficult to introduce doctors; the structure of professional titles is olive-shaped, with intermediate tiles the most and the senior and junior titles the least; the source structure of teachers is single, with most of them directly graduating from colleges. Overall, this structure fails to meet the needs of application-oriented universities. It is therefore crucial to build a professional training mechanism and improve teachers' practical ability.

The construction of the teaching team can be driven in multiple dimensions. First, their practical ability should be strengthened, and applied knowledge be well prepared. Besides, the structure of teaching staff needs to be improved. For example, part-time and full-time teachers might be combined to refine "double-qualified" teachers. In addition, we should put people first, renovate the management ideas and give play to the subjective value of teachers.

\section{The Construction of a "Double-Qualified" Teaching Team in Application-Oriented Universities}

"Double-qualified" teachers are a core feature of application-oriented universities. This character is related to the value of talent cultivation, the construction of the teaching team and the reform of teaching. The current situation of "doublequalified" teachers can be analyzed from the aspects of quantity, quality, training, evaluation, and management (Xu, 2013).

In terms of quantity, there is still a large gap between the proportion of "double-qualified" teachers and the expective figure required by the college transformation. In terms of quality, "double-qualified" teachers generally lack the experience and opportunities of doing practical work in industries and enterprises, which has to a large extent hindered their practical ability. As for training, although most application-oriented universities at present have a particular budget for "double-qualified" teachers' development, it is not enough to guarantee a good result. The limited budget also causes difficulties in recruiting experienced teachers.

With respect to evaluation, the criteria to assess "double-qualified" teachers are not clear (Liu, 2017). A common way to identify a "double-qualified" teacher is based on certificates; that is, whoever holds two certificates can be considered as a "double-qualified" teacher. Regarding the management, application-oriented universities have already paid due attention to the system construction of "double-qualified" teachers. Specifically, the system of access, evaluation incentive, research management and reward have been formulated to ensure the smooth progress of "double-qualified" teacher training.

In short, practical difficulties of building up a "double-qualified" teaching team mainly lie in a shortage of qualified staff, an imperfect training mechanism and an unclear evaluation standard. Considering these situations, we should emphasize designing specific policies to clarify the significance of "double-qualified" teachers and construct a standardized evaluation and development system.

\section{The Construction of a Part-Time Teaching Team in Application-Oriented Universities}

With the transformation of higher education from denotation development to connotation development, especially in the 
current period when local ordinary undergraduate colleges are transitioning into application-oriented ones, the introduction of part-time teachers is of great significance to alleviate the structural contradictions of higher education and the difficulty of graduates' employment and low employment quality. Part-time teachers also add diversity to the homogeneous tendency and contribute to the construction of a "double-qualified" teaching team in application-oriented universities.

Moreover, building a strong part-time teaching team meets the need for school transformation and development. It contributes to a realization of talent-cultivating goals for application-oriented universities, and it also serves their longterm development agenda. At the same time, strengthening the construction of a part-time teaching team helps to optimize the allocation of teachers by alleviating the shortage of professional teachers. Besides, a strong part-time teacher team is beneficial to reduce the financial pressure of universities by, for example, cutting the cost and improving the efficiency of running a school. It is also conducive to improving teaching quality and strengthening school characteristics. Further, it enhances the relationship between universities and societies through the integration of production, education and research. Therefore, establishing a stable part-time teaching team, improving their teaching ability and ensuring teachers' sustainable development have become major issues to be urgently solved by application-oriented universities (Wu, 2021).

Current situations of part-time teachers can be analyzed in terms of number, job title, degree structure and job positions. The number of part-time teachers has steadily increased whereas its proportion is relatively low. In addition, there is a lack of high-level part-time teachers: those with intermediate and senior associate titles take the most share, followed by those with junior and non-professional titles. The ratio of doctoral degrees increased, but the majority of these teachers have only associate degrees or even below. In terms of post responsibilities, part-time teachers mainly teach core courses, and the percentage of part-time "double-qualified" teachers is not high.

Two reasons might explain the above difficult situation. On the government side, it fails to provide sufficient legal support, design systematic policies, or offer enough budget to these part-time teachers. On the school side, part-time teachers are not well-managed because of an inadequacy of the system. Schools also lack reasonable recruitment plans (Xu, 2013).

Given the above situations, the construction of a part-time teaching team can be implemented from the following four aspects. The first is to improve existing laws and policies and develop financial support channels. Teachers' legitimate rights and interests cannot be guaranteed without improved laws and regulations. Education management policies should also be modified to appropriately increase the proportion of part-time teachers. The financial support can never be overestimated as it provides material guarantees for the construction of part-time teachers. The second approach is to open up recruitment channels for part-time teachers and focus on introducing high-tech and high-skilled talents. Universities need to determine the qualifications of part-time teachers and formulate the recruitment conditions. Opening up multiple talent recruitment channels and expanding the source of part-time teachers may work as well. Establishing a database of potential part-time teachers and paying attention to the introduction of high-tech and high-skilled talents are also worth trying. The third is to improve the management level for part-time teachers and promote the value of part-time teachers. After hiring part-time teachers, application-oriented universities should strengthen the construction of a teacher management system, carry out humanized and standardized management, establish and improve the training mechanism, pay attention to their career development, and promote the expansion of their work responsibilities based on the whole process of talent cultivation. The fourth is to implement the people-oriented management concept and establish an effective evaluation and incentive mechanism for part-time teachers. Such a mechanism needs to be continuously perfected to ensure a good teaching quality $(\mathrm{Li}, 2018)$. Great importance should also be attached to the incentive effects. Universities can establish diversified incentive measures to raise part-time teachers' income. An example can be the cooperation between schools and enterprises, which not only gives full play to the educational value of part-time teachers but also achieves mutual benefits between teachers, schools and enterprises.

\section{Teacher Education in Application-Oriented Universities}

A strong teaching team often decides whether local colleges and universities can be successfully changed into applied technology universities, which is especially true for new undergraduate universities. Teacher training, as an important part of the construction of a teaching team, plays a valuable mediating role between teacher planning, qualification access, evaluation and teacher quality. Although many achievements have been made in the teacher training of applicationoriented universities, there are still some problems. For example, there is a lack of specialized training institutions for application-oriented teachers, and the current training model cannot meet young teachers' development needs. Another problem is the imbalance between supply and demand, which fails to cater for diversified training needs. The training content is not so well-targeted to guarantee its training quality. Nor is the management and evaluation system perfect enough.

Several measures might be taken to address the above issues. Firstly, teachers' professional capacity development centers should be set up, and their value brought into play. Secondly, we need to pay attention to on-campus training to improve 
the professional level of existing teachers. This can be done by three stages: pre-employment, in-service adaptation and post-employment improvement. Thirdly, it is necessary to bring in talents reasonably with different training modes and gradient constructions. When introducing high-level talents, we need to focus on cultivating academic leaders and establishing and improving the training path for young teachers. Besides, strengthening the training of young teachers acts as an effective approach to optimize the educational structure, title structure and subject structure, and also a significant way for teachers to absorb new knowledge, broaden their horizons and improve their innovative ability. Specific training can be quite flexible, such as teachers off-campus exchange learning and on-campus training (Dong, 2009).

\section{School-Enterprise Cooperation to Improve Teachers' Practical Ability}

School-enterprise cooperation is an important form of serving society for application-oriented universities. This cooperation can best complement, allocate and share the advantages and resources of both universities and enterprises. It is also a mutually beneficial and win-win project that can improve the comprehensive school-running ability and brand influence of application-oriented universities and promote the innovation level and the competitiveness of enterprises. For teacher construction in application-oriented universities, such cooperation can increase the number and quality of applied teachers and promote the optimization of the part-time and full-time teacher structure. Besides, as a valuable way for teachers to serve society, it can enhance teachers' ability of applied research and practical teaching.

As the main theme of applied higher education, practical teaching is essential for the development of applied teachers. However, most teachers come from the academic circle, working from one school to another. In this case, to accelerate the transition of college teachers from traditional academic to application-oriented, only the adaption of the evaluation system is not enough. What we need are platforms for teachers' practice and various forms of school-enterprise cooperation. Specific measures may involve: (1) building a special leading group to clarify the work process and content of school-enterprise cooperation; (2) formulating and implementing the teacher-to-enterprise practice system; (3) establishing a unique teacher training base with scientific management; (4) integrating and optimizing practical teaching resources inside and outside of school and implementing entrusted training; (5) promoting in-depth cooperation with enterprises by exchanging posts; (6) driven by projects, sending teachers to the front line of production, scientific research and social practice; (7) exploring the co-construction of industrial colleges with enterprises (Liu, 2017).

\section{The Evaluation and Incentive Mechanism for Teachers in Application-Oriented Universities}

The evaluation and incentive mechanism serves as the basis for personnel management, such as teacher selection, appointment, salary, rewards and punishments. It also acts like a "baton" to mobilize teachers' enthusiasm and initiative in teaching, scientific research and serving society. Strengthening the construction of teacher evaluation and incentive mechanisms, therefore, is not only a breakthrough for the transformation of application-oriented universities, a practical need for teachers' professional development, but also an urgent need to stimulate teachers' enthusiasm for cultivating applied talents.

However, there are still at least three difficulties regarding the existing teacher evaluation and incentive mechanisms. First, the positioning of teacher evaluation is not well-targeted. At present, many application-oriented universities still follow the orientation of "emphasizing scientific research and neglecting to teach" in the evaluation of teachers' teaching, research and practical ability. This is contrary to the school's positioning and development strategy and is not conducive to the professional growth of teachers (especially young teachers). Second, there is a lack of a scientific and reasonable evaluation index system. The current evaluation index system in most application-oriented universities lacks universality, and its designation is not supported by strong evidence. The evaluation index of "double-qualified" teachers is not scientific enough. Third, the incentive mechanism to guide teachers' growth is deficient. Although relevant policies are not uncommon in most application-oriented universities, in practice, problems still exist. For example, teachers' subjectivity is often neglected during the policy designing process, resulting in an incentive mechanism that fails to guide the growth of young teachers. In addition, an effective incentive mechanism for "double-qualified" teachers has not yet been established. Therefore, to realize long-term development in the context of higher education transformation, it is an urgent task for application-oriented universities to build scientific management and effective evaluation and incentive mechanism, and then guide the construction of teaching staff.

First, we can design a teaching-centered evaluation standard based on the school transformation plan and build a multidimensional system that involves various teaching stakeholders. This system pays attention to students' evaluation, teachers' self-evaluation and peer evaluation. Second, a teacher evaluation index system should be developed based on the goals of school transformation. In this process, multiple agents are allowed to participate. Quantitative indicators and implicit achievement evaluation are supposed to be combined to guide teachers' development. Third, we should build a double-factor incentive mechanism. Among them, the basic principles should adhere to the combination of material and spiritual motivations and the combination of general incentives and individual incentives. A result-oriented developmental 
incentive mechanism could play a role, and at the same time, particular attention needs to be paid to the relative stability and dynamic adjustment during the implementation process. In terms of the salary distribution system, the material needs of teachers should be satisfied first, and their actual needs considered as well. Such a system should be gradually improved to make teachers "busy". Additionally, non-economic remuneration ought to be used to meet teachers' spiritual needs. For example, we can create a campus culture that respects teachers and values education and highlight the dominant position of teachers. After all, a vibrant, harmonious and orderly environment is necessary to support teachers' development. Another example is to establish a benign training mechanism to meet teachers' self-realization needs.

\section{Conclusion}

To sum up, application-oriented universities are different from traditional academic universities. Compared with a "discipline logic," application-oriented universities emphasize an "application logic;" that is, they contribute to economic development through skill training, research and application. This unique characteristic determines the "applicability" of the construction of teaching staff. Teachers in such universities should first be teachers who integrate knowledge and practice and pay more attention to the transformation and application of knowledge. Starting from this logic, in order to build a good team of teachers in applied universities, it is essential to first clarify the goal-the core literacy and key ability of applied teachers. Then based on this goal, universities should construct a comprehensive system for the teaching team and provide an effective support mechanism for their growth and all-around development. This can be achieved by working on the teacher development orientation, the "double-qualified" teacher structure, the part-time teacher management mechanism, the incentive and evaluation mechanism and teacher training. The expected outcome will contribute a unique experience model and development wisdom to the construction of higher education teachers in China. Therefore, we should encourage universities to explore and practice boldly in the construction of teaching staff, eliminate inherent shortcomings, innovate existing systems and mechanisms, revitalize unique resources and social forces, empower teachers and stimulate their vitality, and pave a new way for the construction of teachers in China's application-oriented universities.

\section{References}

Dong, Y. (2009). Research on the construction of part-time teachers in Higher Vocational Colleges in Tianjin. (Master's thesis, Tianjin University, Tianjin, China).

Li, J. (2018). Discussion on the management of part-time teachers in Applied Universities from the perspective of human resources development. Education and occupation, 22, 97-100.

Liu, J. (2017). Research on the construction of teaching staff in Applied Undergraduate Colleges. (Master thesis. Tianjin Vocational and Technical Normal University, Tianjin, China).

Pan, M. (2006). Preface to the Road of Building Application-oriented Universities. Beijing: Peking University Press.

Pan, M. (2008). On the orientation, characteristics and development of Newly-built Undergraduate Colleges and Universities. Journal of Jingmen Vocational and Technical College, 07, 1-4.

Song, G., Li, Y., \& Liu, Y. (2015). Practical innovation ability is the key to the cultivation of applied talents. China Higher Education, 13, 65-67.

$\mathrm{Wu}, \mathrm{X}$. (2021). Research on the construction of talent training system of undergraduate vocational education: an analysis from the perspective of technology essence. Chinese Vocational and Technical Education, 92, 52-57.

$\mathrm{Xu}, \mathrm{H}$. (2013). Research on the management of part-time teachers in colleges and universities. (Master thesis, Tianjin Normal University, Tianjin, China).

\section{Copyrights}

Copyright for this article is retained by the author(s), with first publication rights granted to the journal.

This is an open-access article distributed under the terms and conditions of the Creative Commons Attribution license which permits unrestricted use, distribution, and reproduction in any medium, provided the original work is properly cited. 